\title{
Ferramenta de autoria multimídia para ensino de língua estrangeira em ambiente multiagente
}

\author{
Adroaldo Guimarães Rossetti \\ Almir dos Santos Albuquerque \\ Vasco Pinto da Silva Filho \\ José Leomar Todesco \\ Fernando Álvaro Ostuni Gauthier \\ Universidade Federal de Santa Catarina
}

Correspndência:

Adroaldo Guimarães Rossetti

Univ. Federal de Santa Catarina

PPG/Eng e Gestão Conhecimento

Campus Universit - Trindade - CP 476

88040-970 - Florianópolis - SC

E-mail: adroaldo@cnpat.embrapa.br

\section{Resumo}

A comunicação é essencial nas atividades do mundo globalizado, onde conhecimento e tecnologia são a chave do progresso. Dominar outros idiomas nesse cenário é vital para a sustentação das pessoas no exercício de suas atividades. 0 sistema de ensino de línguas estrangeiras no Brasil, tanto nas escolas públicas quanto em parte das escolas particulares, não oferece condições para que as pessoas adquiram conhecimentos sólidos de língua estrangeira, conforme suas potencialidades e disponibilidades de tempo, sem prejuízo de outras atividades que exerçam no seu cotidiano. O objetivo deste artigo é apresentar uma ferramenta de autoria multimídia para ensino de língua estrangeira, disponível continuamente na lnternet, que possa ser acessada de qualquer local e a qualquer momento. A ferramenta será construída baseada em arquitetura multiagente, constituindo um ambiente compartilhado semelhante à cooperação entre pessoas, cumprindo eficazmente a tarefa de ensino. Os idiomas, inicialmente inglês e francês, constarão de três módulos: básico, intermediário e avançado. Após ser disponibilizada na Web, a ferramenta será validada com base na crítica dos usuários por cerca de seis a doze meses e será avaliada periodicamente pelos gestores do programa. A ferramenta propiciará o acesso ao aprendizado eficaz de idiomas estrangeiros a quaisquer interessados, de acordo com suas potencialidades, seus interesses e tempo disponível.

\section{Palavras-chave}

Ferramenta de autoria multimídia - Ambiente de ensino e aprendizagem - Língua estrangeira multimídia - Arquitetura multiagente. 


\title{
Multimedia authorship tool for the teaching of foreign languages in a multi-agent environment
}

\author{
Adroaldo Guimarães Rossetti \\ Almir dos Santos Albuquerque \\ Vasco Pinto da Silva Filho \\ José Leomar Todesco \\ Fernando Álvaro Ostuni Gauthier \\ Universidade Federal de Santa Catarina
}

\begin{abstract}
Communication is essential in the activities of a globalized world in which knowledge and technology are the keys to progress. In this scenario, having command of other languages is a vital support for people in their activities. The system for teaching foreign languages in Brazil, both in public schools and in part of the private institutions, fails to offer the basic conditions for people to acquire solid knowledge of a foreign language, according to their potential and time availability, and without affecting the other activities they develop in their daily lives. The objective of the present paper is to introduce a multimedia authorship tool for the teaching of a foreign language, which is continually available on the Internet and therefore accessible from any place at any time. The toll will be built based on a multi-agent architecture constituting a shared environment similar to people's cooperation, fulfilling effectively the task of teaching. The languages, initially English and French, will comprise three modules: basic, intermediate and advanced. After being available on the Web, the tool will be validated by user criticism during a period from six to twelve months, and will be periodically assessed by the managers of the program. The tool will afford access to effective learning of foreign languages to anyone interested, according to their potentiality, interests, and time available.
\end{abstract}

\section{Keywords}

Multimedia authorship tool - Teaching and learning environment Multimedia foreign language - Multi-agent architecture.

\footnotetext{
Contact:

Adroaldo Guimarães Rossetti

Univ. Federal de Santa Catarina

PPG/Eng e Gestão Conhecimento

Campus Universit - Trindade - CP 476

88040-970 - Florianópolis - SC

E-mail: adroaldo@cnpat.embrapa.br
} 
A agilidade do progresso no mundo globalizado, nas comunicações, na tecnologia e nas atividades organizacionais exige cada vez mais que as pessoas tenham conhecimento de outros idiomas, além do seu, a fim de manterem uma atuação sustentável no exercício de suas atividades. Nesse contexto, o domínio da língua inglesa, por exemplo, predominante em praticamente todas as áreas do conhecimento e das atividades, aparece como uma necessidade quase de sobrevivência na vida das pessoas. Apesar de essa realidade ser praticamente uma consciência nacional, o ensino oficial no Brasil, ao que tudo indica, não parece apontar uma saída para suprir essa necessidade em curto prazo.

A Lei de Diretrizes e Bases da Educação Nacional (LDBEN) n. 9394, de 20 de dezembro de 1996 (Brasil, 1996), no artigo 24, trata da educação básica, nos níveis fundamental e médio. 0 inciso IV desse artigo menciona que:

\section{[...] poderão organizar-se classes, ou turmas, com alunos de séries distintas, com níveis equivalentes de adiantamento na matéria, para o ensino de línguas estrangeiras [...].}

Até onde se sabe, no entanto, isso ainda não parece ser uma realidade, pelo menos nos estabelecimentos oficiais, onde o ensino é oferecido pelo estado brasileiro. Ao que se tem conhecimento, cumpre-se apenas o estabelecido no $\S 5^{\circ}$, do artigo 26 , no qual é citado que

\section{[...] na parte diversificada do currículo será incluído, obrigatoriamente, a partir da quin- ta série, o ensino de pelo menos uma língua estrangeira moderna, cuja escolha ficará a cargo da comunidade escolar, dentro das possibilidades da instituição.}

Apesar de não se explicitar a "língua estrangeira moderna”, geralmente prevalecem, na maioria das regiões do país, o inglês e o francês. Essa prevalência é uma nítida expressão do reconhecimento da importância da língua inglesa, por exemplo. Convém registrar, contudo, que em regiões com forte influência de imigrantes (alemães, italianos, japoneses etc.), como no Sul e Sudeste, essa predominância é menos acentuada.

Mesmo com a inclusão, "obrigatoriamente a partir da quinta série”, independente do idioma, essa condição não oferece além de noções elementares principalmente por duas razões. Primeiro, porque o ensino dessa língua não atravessa continuamente todo o período, como induz a expressão "a partir". Segundo, a exiguidade da carga horária não permite maiores avanços e para por aí, longe de propiciar condições de um bom aprendizado de língua estrangeira. Exceto para aqueles que ingressam na universidade, num curso de Letras, onde realmente se especializam em alguma língua, há poucas alternativas para aprofundar conhecimentos nessa área. Resta, pois, buscar os institutos e as escolas particulares de línguas estrangeiras, para que se adquira conhecimento adequado, cujos custos, quase sempre elevados e horários inflexíveis, em geral impedem que uma fatia considerável da população se insira nesse processo.

Algumas concepções linguísticas existentes em softwares educativos comportam duas etapas: uma consiste na análise estrutural da sequência oriunda da base; a outra, de uma mudança estrutural dessa sequência. Nessa premissa, apoia-se a concepção linguística deste trabalho, que parte de uma análise da situação do ensino de língua estrangeira no Brasil, para então discutir as possíveis transformações provocadas pelo modelo proposto. A concepção metodológica, por sua vez, centra-se no estudo e na análise dos problemas de ensino de língua estrangeira no Brasil, identificando os fatores causais que serão considerados pela intervenção da ferramenta proposta.

No ensino tradicional de língua estrangeira, normalmente as aulas são ministradas em dias e horários determinados pela escola, de acordo com um calendário prefixado, quase sempre inflexível. Essa sistemática, que não deixa de ter seus aspectos positivos, pode trazer prejuizos a alunos que, por algum motivo, 
venham a ser impedidos de assistir a uma ou mais aulas sucessivamente. Idêntico empecilho pode infligir àqueles que por alguma circunstância sejam eventualmente impelidos a uma paralisação temporária de frequência às aulas de determinado módulo do curso, independente do estágio em que se encontre o módulo. A ocorrência de qualquer desses casos poderá causar aos alunos perda da sequência do assunto lecionado, dificultando-lhes prosseguir o curso com bom aproveitamento, uma vez que, em casos dessa natureza, as aulas perdidas dificilmente podem ser recuperadas paralelamente ao curso normal por diversos fatores. Quando são muitas, o próprio tempo necessário pode inviabilizar o processo; quando são poucas e o tempo comporta, os elevados custos normalmente impostos podem ser inexequíveis a muitos alunos. Por outro lado, alunos que têm maior facilidade de aprendizado de outro idioma com condições de progredir mais rapidamente são, às vezes, também penalizados, uma vez que essa estrutura geralmente não comporta a formação de turmas que levem em consideração essa característica. E quando isso é possível, em geral as turmas têm poucos alunos, o que eleva bastante os custos, tornando-se um fator impeditivo para muitos. Nessas circunstâncias, aguardar o início de uma nova turma do mesmo nível ou módulo tem sido uma alternativa para quem deseja fazer um bom curso, embora isso implique em aumentar o tempo de aprendizado ou domínio da língua em estudo.

Situações não muito diferentes enfrentam trabalhadores que desejam aprofundar seus conhecimentos, às vezes, até por necessidade profissional. Nesse sentido, Pettenati et al. (2000) mencionam que devido às distâncias ou às dificuldades de conciliar compromissos organizacionais, muitas pessoas enfrentam dificuldades para progredir na aquisição de conhecimento e competência, pois na maioria das vezes, esses aspectos dependem de um professor nem sempre disponível nas organizações.

Portanto, a falta de flexibilidade para iniciar ou reiniciar um curso, particularmente de língua estrangeira em qualquer período, horário ou local, é um problema a ser resolvido devido à importância do professor nesse tipo de ensino e aprendizagem. Nesses cursos, mais do que em qualquer outro, aspectos como pronúncia, percepção auditiva, repetição, leitura e escrita, por exemplo, têm grande importância e são objetos de orientação, via material de ensino e exercícios, pelo professor. Além disso, essas características constituem praticamente as quatro habilidades de linguagem: compreender a linguagem oral, falar, ler e escrever, em cujas bases, segundo Widdowson (1991), são definidos os cursos de línguas estrangeiras. Essas habilidades referem-se aos tipos de atividades que os alunos devem realizar ao cursar um idioma qualquer, com as quais muitos professores concordam. Portanto, devem ser também a base para a geração de material didático desses cursos.

Urge, pois, que se disponha de uma estrutura flexível, que permita ao interessado iniciar o curso em qualquer período, horário e local, de acordo com suas possibilidades, conveniências e com o nível de conhecimento que já possui do idioma a ser cursado. $\mathrm{Ou}$ a sua retomada, a partir de onde eventualmente tenha ocorrido uma paralisação. Além disso, que permita àqueles que têm maior facilidade de aprendizagem a possibilidade de completar os estudos, com maior rapidez, de acordo com suas habilidades, necessidades, disponibilidade ou conveniências. É essencial que haja, nessa estrutura, material didático, textos, orientação para leitura (reading) e escrita (writing); sons e imagens que reflitam clareza da pronúncia e desenvolvam habilidade de percepção auditiva (listening); exercícios direcionados para aperfeiçoar a pronúncia, a grafia correta das palavras e a fluência (conversation). É importante também que porte boa dosagem de incentivo e que motive o aluno a acelerar o processo de aprendizagem.

Hoje, no entanto, segundo Pettenati et al. (2000), essas barreiras são plenamente transponíveis com o auxílio da tecnologia da informação e comunicação (Information and Communication Technology - ICT). 
0 uso da tecnologia nesse processo é fundamental, pois, para Ramos (1996), a incorporação da tecnologia ao processo educativo oferece, concretamente, a oportunidade de se implementar um novo modelo ou padrão pedagógico. Além disso, a tecnologia tem potencial para produzir novas e ricas situações de aprendizagem. Segundo Coutaz (1990), aquele que concebe um sistema interativo deve elaborar uma descrição, a mais precisa possível, do problema e dos processos cognitivos do usuário, de modo que lhe venha não apenas dar suporte, mas lhe motivar, cada vez mais, ao processo de aprendizagem.

Segundo Kaskalis, Tzidamis e Margaritis (2007), com a explosão da computação multimídia, educadores têm tentado trabalhar uma forma de realizar uma completa interação humanocomputador, buscando favorecer o progresso de ensino e aprendizagem. Consequentemente, um grande número de ferramentas multimídia tem sido criado, sempre seguindo a tendência de um desenvolvimento mais simples e mais fácil dessas ferramentas. Muitas ações têm sido executadas para facilitar esse intento: desde a utilização de múltiplos recursos computacionais até a introdução de uma série de variáveis para basear uma avaliação apropriada. Até agora, entretanto, conforme esses autores, não há notícia de alguma ferramenta que tenha cumprido totalmente essa tarefa.

Para Bailey e Konstan (2000), a falta de uma ferramenta de autoria que favoreça interação satisfatória do processo de ensino e aprendizagem ocorre porque, embora essas ferramentas sejam em geral desenvolvidas por excelentes profissionais da área de computação, nem sempre têm a necessária cooperação de especialistas no assunto a que se destina a ferramenta. Além disso, raramente são validadas com a participação do destinatário usuário final.

Para Bulterman e Hardman (2005), um grande número de ferramentas de autoria multimídia, normalmente, não faz mais que limitar as características disponíveis (especialmente em sistemas comerciais) para reduzir a complexidade artificialmente. Esses autores mencionam que a construção de apresentações multimídia, uma tarefa que não é trivial, deve considerar os contextos sensiveis e interativos, transmitidos em rede. Citam, além disso, que uma apresentação multimídia tem que descrever uma coleção abstrata de conteúdo do candidato e ter exemplos a serem apresentados ao usuário.

Para Moran (2003), com a evolução das tecnologias digitais, surgiu a educação on-line como uma excelente alternativa para o avanço do conhecimento. Para esse autor, a educação on-line envolve um conjunto de ações de ensino e aprendizagem desenvolvido com o emprego de meios telemáticos, como a Internet, e o uso de todos os seus dispositivos informacionais e comunicacionais, úteis ao aprimoramento de processos inter-relacionais.

\section{Revisão técnica}

Os avanços tecnológicos têm favorecido a implementação de ferramentas de apoio aos processos de ensino convencional de língua estrangeira na tentativa de melhoria dos métodos de ensino e aprendizagem, como as utilizadas por Courtillon e Raillard (1983) na Aliança Francesa, por exemplo. A execução dessa prática consiste em usar o computador como instrumento de auxilio ao ensino da língua francesa, utilizando os recursos multimídia para ouvir, falar e escrever.

Várias outras iniciativas têm sido tomadas com o uso da tecnologia, visando dar acesso ao conhecimento ao maior número possível de pessoas. Em vista disso, Pettenati et al. (2000) propuseram uma ferramenta para ensino a distância, a fim de disponibilizar a instrução, sem prejuízo do trabalho, tornando-a mais acessivel e eficaz a quem estiver interessado, particularmente trabalhador e empresa. A ferramenta proposta descreve um webbased, autor de um sistema tutor de aprendizagem, concebido para suprir as dificuldades de distância ou de compromissos organizacionais. 0 ambiente é composto por diversos sistemas interconectados, entre os quais: 
1. Descrição do curso, com direcionamento e agenda;

2. Plano de trabalho e temas para revisão dos assuntos estudados; e

3. Uma estrutura que facilita a autoavaliação periódica.

É uma ferramenta que, segundo os autores, vem cumprindo a contento os objetivos a que se propôs.

Sob a ótica da evolução tecnológica na área pedagógica, a Engenharia do Conhecimento, via utilização de técnicas de Inteligência Artificial (IA), pode ser o caminho para oferecer opções a quem deseja ampliar seus conhecimentos. Foi exatamente com a IA que surgiram os primeiros sistemas voltados para o ensino através de computador, como o treinamento baseado em computador (Computer Based Training - CBT), mencionado por McArthur, Lewis e Bishay (2002), e a instrução baseada em computador (Computer Assisted Instructional - CAl), referida por Beck, Stern e Haugsjaa (1996). Segundo esses autores, o sistema citado pelos primeiros usualmente gerava conjuntos de problemas projetados para aumentar o desempenho do estudante em domínios baseados em habilidades como aritmética e recuperação de vocabulário. Além disso, as decisões sobre como o estudante deveria navegar através do material eram baseadas em árvores de decisão e a sequência de perguntas e respostas era dirigida pelos acertos e erros do estudante, não sendo consideradas suas habilidades individuais. Para Urban-Lurain (1998), as propostas preconizadas nesses sistemas limitavam-se a apresentar um problema ao estudante: registrar a resposta e avaliar seu desempenho, mas as instruções não eram individualizadas para as suas necessidades.

Virvou e Moundridou (2000) utilizaram um Sistema de Tutores Inteligentes para desenvolver uma ferramenta de autoria para a Web, destinada ao uso de professores e estudantes no domínio de equações algébricas. No acesso à ferramenta, há uma "descrição" de um domínio específico, dado por um professor humano.
A ferramenta fornece ajuda ao professor humano na construção de exercícios e, enquanto os estudantes resolvem os exercícios, "monitores" fornecem o gabarito apropriado. Ela incorpora inteligência em seu componente que executa diagnose para os erros dos estudantes. Controla também o material pedagógico de modo flexível e individualizado e executa análise inteligente das soluções dos estudantes, fornecendo apoio interativo para resolver problemas. Além disso, o sistema adapta e anota os tipos de ligações que os estudantes fazem entre as suas soluções e o apoio recebido. As vantagens desse sistema, segundo Virvou e Moundridou (2000), é que os tutores humanos colaboradores podem estar no mesmo local físico ou a distância e os estudantes podem estar numa classe, em um local específico, ou em uma classe virtual, que pode ser espalhada por muitos locais físicos, promovendo assim aprendizagem a distância.

Visando responder à pergunta: é possível conseguir ambientes de aprendizagem eficazes de uma ferramenta genérica, aplicável a todos os contextos do conhecimento, ao longo do período de vida de aprendizado? Ainsworth (2007) desenvolveu um ambiente de autoria denominado REDEEM, que se propôs a alcançar esse objetivo, adaptando ambientes de aprendizagem interativos de software de autoria multimídia (multimedia authoring software ou courseware) existentes. 0 REDEEM foi desenvolvido no instrutor Click2Learn ToolBook e é executado na plataforma Windows. O software consiste de duas partes principais (a ferramenta de autoria REDEEM e uma shell), por meio das quais os "autores" e estudantes interagem no courseware. Os cursos existentes no ToolBook são, entre outros, tópicos de genética; sistemas de informação e comunicação; PCs e gestão de redes; cursos de html: de estatísticas e princípios de fotografia, por exemplo. A primeira maior tarefa a ser executada é descrever o material de domínio, que o sistema usará para tomar decisões sobre como apresentar esse material aos estudantes. 0 segundo maior as- 
pecto de domínio da autoria é adicionar interatividade. Os "autores" criam perguntas (escolha múltipla, preencher o espaço em branco, múltiplo verdadeiro, verdadeiro-falso ou perguntas combinadas) e fornecem o gabarito que explica ao estudante porque uma resposta está correta. Podem ser criadas cinco sugestões diferentes para cada pergunta, o que segundo Ainsworth (2007) aumenta a especificidade. Os "autores" descrevem também várias características da pergunta que a shell usa para implementar uma estratégia específica de ensino (dificuldade, pré ou pós-teste, por exemplo). Podem, além disso, associar pontos de reflexão (como meios para que os estudantes fiquem alertas para tomar notas) ou sobre uma tarefa não de computador (que dirige a atenção do estudante a outra atividade). Ainsworth (2007) acompanhou o REDEEM durante dez anos, comparando-o com outros coursewares e o descreve como um dos mais utilizáveis e fáceis de aprender. Reconhece, contudo, que devido ao caráter genérico, alguns benefícios que vêm do rico domínio de conhecimento específico têm que ser sacrificados.

Para Crispim, Abdalla Júnior e Molinaro (2002), um ciclo de ensino deve atender aos seguintes requisitos:

a) Apresentar a informação relacionada ao objetivo do ensino;

b) Direcionar a ação dos estudantes para esses objetivos;

c) Valorizar e avaliar as ações dos estudantes;

d) Fornecer feedback;

e) Fornecer estratégias de orientação para o aluno;

f) Administrar e motivar todo o processo de ensino.

Diante disso, eles afirmam que a grande maioria dos ambientes clássicos de ensino a distância apresenta limitações na implementação da interação entre o aluno e o ambiente de ensino. Esses autores desenvolveram um ambiente utilizando técnicas de inteligência artificial, especificamen- te redes Bayesianas (que se baseiam na força de sua representação causal, na facilidade de representação do raciocínio humano e na habilidade de representar e responder às mudanças de configurações); redes neurais (que procuram aproximar o modelo de processamento dos computadores ao do cérebro humano, por possuírem um grau de interconexão similar à estrutura do cérebro e, num computador convencional moderno, a informação é transferida em tempos específicos dentro de um relacionamento sincronizado); workflow (que facilita a organização do conhecimento a ser transferido ao aluno pela criação de um conjunto de caminhos, focados em diferentes níveis de explicações e respectivos exercícios para teste de aprendizado da disciplina); e softwares agentes ou agentes inteligentes (devido às suas características de: habilidade de explorar uma soma significativa do domínio de conhecimento; tolerância a erros inesperados ou resultantes de entradas errôneas; habilidade no uso de símbolos e abstrações; capacidade adaptativa e comportamento orientado ao objetivo; habilidade de aprender com o ambiente; capacidade de operação em tempo real; e habilidade de comunicação em linguagem natural). Para Crispim, Abdalla Júnior e Molinaro (2002), a arquitetura apresentada corresponde ao modelo de inclusão de mecanismos de raciocínio no ambiente de ensino que será responsável pela otimização do processo de construção, transmissão de conhecimento e aprendizagem inteligentes.

Um passo importante nessa direção foi dado por Barr, Cohen e Feigenbaum (1990) com o desenvolvimento de Sistemas Tutoriais Inteligentes (Intelligent Tutorial Systems - ITS), cujo principal objetivo, conforme Clancey e Soloway (1990), era reproduzir o comportamento inteligente (competente) de um tutor humano, e poder adaptar sua maneira de ensinar ao ritmo de aprendizagem do aluno. Nesse contexto, segundo Lévy (2000), os correios e as conferências eletrônicas servem como tutores inteligentes e podem ser colocados a serviço de dispositivos de aprendizagem cooperativa. Os suportes hipermídia (CD-ROM, bancos de dados multimídia interativos on-line) permi- 
tem acessos intuitivos rápidos e atraentes a grandes conjuntos de informações.

Várias aplicações vêm sendo desenvolvidas, empregando sistemas multiagentes no processo de ensino e aprendizagem, entre os quais se pode destacar, por exemplo, o Sistema Multiagentes de Ensino e Aprendizagem na Internet - SEMEAl. Conforme Geymer et al. (2003), esse sistema tem como objetivo promover o aprendizado a distância, usando a tecnologia de agentes para adaptarse às características particulares do estudante. Tal ocorre aplicando formas diferenciadas de ensino que se adaptem aos aspectos psicopedagógicos do aluno, proporcionando uma efetiva retenção na memória devido à diversidade de formas e oportunidade de aprendizagem e a sua adaptação ao aluno. Nesse ambiente, o autor direciona a sua solução, destacando três atividades fundamentais em um sistema de tutoria:

a) Adaptabilidade ao perfil do aluno, com o objetivo de proporcionar maior qualidade na seleção dos materiais disponíveis;

b) Seleção automática de estratégias adequadas de ensino, com base nos resultados obtidos por meio de avaliações realizadas ao longo do processo. 0 ambiente pode levar à adoção de estratégias mais adequadas para conduzir a aprendizagem do aluno em determinado assunto;

c) Personalização do currículo de ensino, mediante um agente específico, responsável por essa atividade. Esse caráter personificado do currículo é definido como a seleção de material de acordo com as táticas estabelecidas em cada método de ensino que compõe a estratégia selecionada.

Fialho e Alves (2001), usando técnicas de Realidade Virtual associadas à Teoria de Agentes Cognitivos, desenvolveram uma ferramenta pedagógica com a finalidade de favorecer a crianças, adolescentes e adultos a aprender, interagir e mergulhar num processo de partilha do conhecimento. Esses autores incentivam a se pensar no desenvolvimento de softwares para Educação
Infantil, por exemplo, com o intuito de melhorar a qualidade de ensino. Isso permite, segundo eles, que o software seja um apoio para a construção do conhecimento de crianças, adolescentes e adultos, e não meramente um sinônimo de "automação" da educação. Isso significa que o desenvolvimento de software educacional deve recuperar valores brasileiros, no caso vertente, visando à aproximação da realidade.

Santos e Osório (2003), com o objetivo de incentivar o seguimento de aprendizagem, apresentaram um ambiente virtual tridimensional inteligente e adaptativo para a Educação a Distância. Nesse ambiente, utilizado para disponibilizar conteúdos, a característica de adaptação está relacionada com as possibilidades de reorganizá-los por meio dos processos de inserção, remoção ou atualização das informações e de personalização da apresentação desses conteúdos, conforme interesses e preferências dos usuários. Para tanto, um perfil de conteúdo e um perfil de usuário são utilizados no processo de adaptação. Além disso, o ambiente é habitado por entidades inteligentes que atuam como assistentes dos usuários durante a navegação e localização de informações relevantes, bem como auxiliam na organização dos conteúdos a serem disponibilizados.

Entretanto, estabelecer esses perfis envolve certa complexidade, cujos elementos em geral nem sempre podem ser particularizados, por isso precisam ser considerados em conjunto. Para Morin (2004), complexidade significa uma tessitura comum que se coloca como inseparavelmente associada. Dessa forma, o indivíduo e o meio, o sujeito e o objeto, a ordem e a desordem, o professor e o aluno, as ações e as "tramas" da vida e os demais tecidos que regem os acontecimentos precisam ser olhados a partir de um contexto geral. Para esse autor, complexo é aquilo que é tecido em conjunto e como tal deve ser considerado. A separação em partes pode levar à perda do contexto. Esse enfoque traz consigo a visão de que o conhecimento é construído a partir de intercâmbios nutridores de relações entre sujeitos e objeto, mediante diálogos, interações, trans- 
formações e enriquecimentos mútuos, em que nada é linear ou preestabelecido, mas relacional, indeterminado, espontâneo, criativo e novo. Sob essa ótica, a tecnologia que hospedar um sistema para ensino e aprendizagem deve conter características que se assemelhem ao comportamento humano dotado dessas faculdades.

Segundo Araújo (2007), o atual modo de ensinar não dá conta das novas evidências acerca da subjetividade humana. Na opinião da autora, já se tem embasamento suficiente para legitimar uma transformação no ensino, sabendo que não se aprende linearmente, mas mobilizando as diversas dimensões do ser humano. Essa mobilização facilitará a reconfiguração do conhecimento ao ser incorporado pelos alunos e ajudará a descobrir e atribuir sentido próprio às informações provenientes quer dos professores e dos textos quer dos diálogos estabelecidos no ambiente de ensino. É desse processo que surge um conhecimento que permite ao aprendiz sobreviver e transcender a partir de uma relação dialética entre o saber e o fazer que se realiza por meio da participação de outras dimensões humanas, entre elas a sensorial, a intuitiva, a emocional e a racional que, sabe-se, são complementares.

Em ambientes on-line fundamentados na perspectiva da interatividade, os conteúdos do curso são construídos num processo de parceria, em que os autores criam e socializam seus saberes de várias formas: por softwares, interfaces, hipertextos e mídias. Araújo (2007) propõe que um ambiente de ensino seja mais interativo, com maior autonomia dos estudantes, com práticas que contemplem os diferentes estilos de aprendizagem e outras que estimulem a construção individual e coletiva do conhecimento.

Se, por um lado, tem sido difícil produzir uma ferramenta de autoria eficaz para ensino multimídia ou a distância, por outro, na opinião de muitos pesquisadores, entre os quais Kaskalis, Tzidamis e Margaritis (2007), encontrar uma forma ou ferramenta para avaliar a eficácia do processo de ensino e aprendizagem das ferramentas propostas é ainda uma questão sem resposta.
Oliver (2000) introduziu um sistema para avaliar o grau de aprendizagem obtido individualmente por experts e por grupos, via procedimento compartilhado. A avaliação, segundo esse autor, é um processo complexo e pode ser caracterizada como um recurso pelo qual as pessoas fazem julgamentos sobre conceitos de valores. No contexto de tecnologia de aprendizagem, contudo, ela se torna muito simples, em sua opinião. A ferramenta proposta por Oliver (2000) oferece um instrumento para análise dessa complexidade, pela comparação dos dois casos (experts e por grupos) acima referidos, cuja conclusão aponta maior grau de aprendizagem ao processo compartilhado. Esse modelo na ferramenta visa fornecer a sustentação apropriada para a gerência de uma organização, no caso; promover a capacitação do seu pessoal; e programar o tempo em processos de aprendizagem a distância, sem prejuizo de suas atividades.

Kaskalis, Tzidamis e Margaritis (2007), visando encontrar uma ferramenta que pudesse servir a uma finalidade puramente educacional, avaliaram separadamente 44 pacotes de ferramentas de autoria multimídia. Coletaram uma quantidade razoável de dados que foram tratados com base numa escala de cinco pontos, sobre cujos resultados as ferramentas foram avaliadas. Relataram a falta de dados relacionados à educação, com vistas a especificar se é possível um pacote de autoria ser usado por educadores (sem perícias particulares) para facilitar um curso em qualquer campo ou assunto. Não encontraram nenhum software para avaliar claramente o papel educacional e concluiram finalmente que, do ponto de vista educacional, nenhuma dessas ferramentas tem algo especial a oferecer a um ambiente de ensino.

Para Collazos et al. (2007), muitas pesquisas sobre o trabalho colaborativo focalizam no grupo a qualidade do resultado como um critério para o sucesso da aprendizagem colaborativa. Há pouca pesquisa sobre o próprio processo de colaboração. Uma compreensão desse processo não só ajudaria a melhorá-lo como propiciaria aperfeiçoar os resultados da colaboração. Para esses autores, compreender e avaliar processos 
de aprendizagem colaborativa requer uma análise refinada da interação do grupo no contexto de objetivos e aprendizagem. Levando em consideração as relações entre tarefas, produtos e colaboração, Collazos et al. (2007) apresentam um conjunto de medidas projetadas para avaliar o processo de aprendizagem colaborativa. Esses procedimentos enfatizam: direção do sistema base; medidas baseadas em dados produzidos pelo sistema de aprendizagem colaborativa durante o processo de colaboração; e sugerem que essas medidas podem ser ampliadas, considerando as percepções de participantes do processo.

0 modelo proposto pelos autores baseiase na mensuração do processo de aprendizagem colaborativa. Para tanto, produziram indicadores de qualidade do trabalho dos estudantes durante as fases do processo de aprendizagem cooperativa, a partir de um modelo de alto nível de aprendizagem colaborativa.

No contexto desses avanços, os sistemas multiagentes, cujos componentes, segundo Oliveira (1998), devem raciocinar a respeito das ações e sobre o processo de coordenação entre si, constituem arquiteturas mais flexiveis, numa organização de sistema que está sujeita a mudanças, visando a adaptar-se às variações do ambiente e/ou do problema a ser resolvido.

Sob essa ótica, o objetivo deste artigo é apresentar uma proposta de ferramenta de autoria, em ambiente multiagente, como instrumento de ensino e aprendizagem de língua estrangeira, multimídia, disponível continuamente na Internet, de forma que os interessados possam utilizá-la em qualquer momento e local, de acordo com suas potencialidades, conveniências e possibilidades, sem prejuízo de outras atividades que eventualmente exerçam.

\section{Material e métodos}

A ferramenta a ser implementada será baseada num sistema multiagentes, segundo a visão de Heilmann et al. (1995), cujos agentes, com “espírito" cooperativo, trabalhando juntos, executarão tarefas mutuamente benéficas, independente de suas complexidades. Essas atividades destinam-se a prestar serviços a estudantes e professores de línguas estrangeiras. Pretende-se que um sistema dessa natureza atue como representante de outrem, com o propósito de desempenhar ações que são benéficas à parte representada.

Os agentes, como entidades de software que fazem um conjunto de operações em favor do usuário ou outro programa com algum grau de independência e autonomia, fazem isso, segundo 0'Connor et al. (1996), empregando algum conhecimento ou representação dos objetivos e desejos do usuário. Por essas características, são, portanto, indispensáveis a uma ferramenta que incorpora justamente essa função de servir, de beneficiar o usuário. Outro aspecto que justifica a opção por um sistema multiagentes para basear a ferramenta proposta são suas propriedades de inteligência (capacidade de perceber dinamicamente o ambiente, realizar ações que afetem as condições do ambiente, entender as percepções, resolver problemas, construir inferências e agir); percepção (habilidade de perceber e responder às mudanças no seu ambiente de execução); aprendizagem (capacidade para executar uma tarefa com maior eficiência do que em execuções anteriores); comunicabilidade (capacidade de comunicar-se com o usuário, com outros softwares agentes ou outros processos); cooperatividade (capacidade de trabalharem juntos para alcançar o objetivo geral por meio de ajuda mútua); mobilidade (capacidade de movimentar-se por si próprios pela rede eletrônica ou mover-se de uma localização para outra, preservando o seu estado interno); veracidade (alto nível de confiança de que o agente representa exatamente o usuário); autonomia (capacidade de operar sozinho e executar ações sem a intervenção do usuário); adaptabilidade (capacidade de processar diferentes níveis de tarefas, de acordo com sua competência); e tantas outras, cujas vantagens são amplamente discutidas por diversos autores como Gilbert e Manny (1996). Tais propriedades permitem implementar estruturas flexíveis, cuja organização se adapta facilmen- 
te às variações do ambiente ou do problema a ser resolvido, daí a razão de sua aplicação em tantas áreas do conhecimento e atividades.

Ao permitir a representação de algumas habilidades de raciocínio e conhecimento especialista na busca de solução de grandes problemas nessa área, essas características favorecem aplicações à atividade escolar e contribuem com novas formas de ensino e aprendizagem. Ao usuário, dão inclusive a possibilidade de construir novas experiências e elaborar ou criar novos modelos mentais, conforme preconizado por Piaget (1983). No caso específico do binômio ensino e aprendizagem de língua estrangeira, o antropomorfismo dos agentes tem particular importância na representação de características humanas como sons, timbres de voz e outras, tão úteis à expressão adequada da pronúncia das palavras, por exemplo.

0 mais relevante nesse aspecto é que os sistemas multiagentes constituem, pode-se dizer, um ambiente de compartilhamento e, como tal, têm reflexo no crescimento e na qualidade do conhecimento. Isso, aliás, é uma característica marcante do capital da era do conhecimento, cujo crescimento acontece na medida em que é compartilhado, em contraposição ao capital da era industrial, por exemplo, que tendia a crescer na medida em que era retido com seu proprietário. Tem-se, pois, a expectativa que esse caráter seja a marca no aprendizado de língua estrangeira com o uso dessa ferramenta.

\section{Proposta}

A ferramenta de autoria multimídia para ensino e aprendizagem de língua estrangeira, baseada em sistemas multiagentes, dará ao aluno, independente do seu nível de conhecimento da língua, maior flexibilidade no sistema de aprendizagem, possibilitando-lhe total controle desse processo. A ferramenta permite que a equipe de desenvolvimento de material educacional multimídia insira facilmente textos e objetos como figuras, sons e vídeo, de forma a criar histórias com diálogos, baseando-se em material didático utilizado para o ensino de língua estrangeira.

Uma arquitetura multiagente busca assimilar a cooperação entre pessoas na sociedade humana para realizarem tarefas que constam na ferramenta e são transmitidas por meio de comunicação e troca de mensagens entre os agentes, visando executar determinadas atividades. Baseado na estrutura proposta na ferramenta, o ensino de língua estrangeira terá a sua aplicabilidade contemplada nessa metodologia tanto para discentes como para o mercado de trabalho em geral. Na proposta aqui apresentada, fundamentada numa arquitetura multiagente, a cada agente, é atribuído um papel específico. Para a realização das tarefas associadas ao papel que desempenham, os agentes implementarão habilidades cognitivas específicas, com plena comunicação e interação entre si, propiciando ao sistema total funcionalidade. Ao contrário de uma solução centralizada numa única base de conhecimento, propõe-se aqui uma estrutura distribuída para o conhecimento, conforme sugerido por Rossetti et al. (2006). Assim, cada agente terá a sua própria base de conhecimento, com as representações necessárias ao melhor tratamento das informações que utilizará na realização de suas tarefas e no compartilhamento e na cooperação com os outros agentes do sistema, como pode ser observado na estrutura conceitual do diagrama da Figura 1.

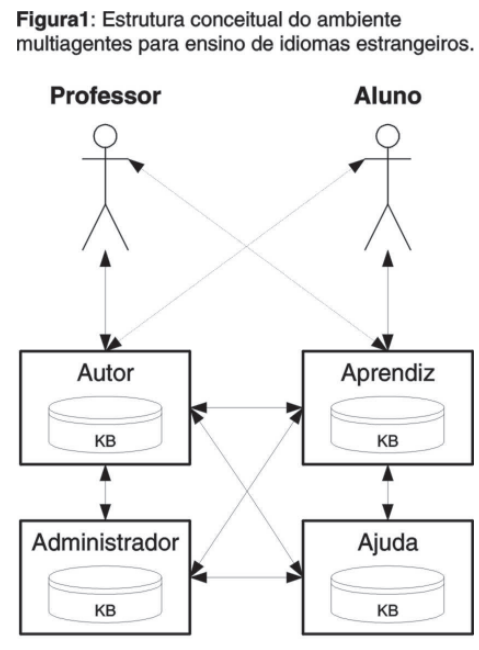

Fonte: Elaboração dos autores. 
Nesse diagrama, os retângulos representam os agentes; nos círculos, estão as bases de conhecimento (Knowledge's Base - KB) do domínio de cada agente; as setas representam as relações (comunicação) entre os agentes; os "bonecos aramados" são atores reais, entre os quais, professor e aluno são os principais. A ferramenta será disponibilizada e acessada através da Internet, na Web, não havendo interação humana direta entre professor e aluno. A interação entre eles ocorrerá indiretamente, por meio dos agentes Autor e Aprendiz, que os representam no ambiente de ensino, e servem de mediadores no processo de exposição e aprendizagem da matéria. Nesse contexto, o agente autor, que é o representante do professor no sistema, terá o conhecimento sobre o domínio da aplicação, que lhe permitirá a elaboração do conteúdo das lições que ministrará, utilizando os recursos multimídia. Essas lições, elaboradas com o apoio dos textosbase, conterão informações sobre o domínio do conhecimento da língua estrangeira a ser ministrada em diversos formatos como texto, som e imagem. Serão criadas situações de aprendizagem voltadas para a percepção auditiva (pronúncia) e para a grafia correta das palavras (escrita). Será, portanto, baseada em audição de textos com acompanhamento visual de cenas para contextualização. Nesse processo, o aluno deverá escrever, em um campo indicado, o texto da língua em estudo, relativo ao que ele ouviu e o sistema fará a verificação do grau de sucesso que ele obteve (total, parcial, insucesso). Imediatamente o sistema interage com ele em feedback até o sucesso total.

Como ilustração desse ambiente interativo, considere-se, por exemplo, que tenha sido criado e gravado pela ferramenta um diálogo em língua estrangeira, cujas imagens são exibidas ao aluno, oferecendo-lhe condições de contextualizar o diálogo. 0 texto escrito não lhe será apresentado. 0 aluno deverá ouvir o diálogo e, quando chegar à conclusão que entendeu o que foi dito, escreverá o que entendeu no campo indicado do texto. 0 sistema então verificará se o aluno: a) Compreendeu e conseguiu reproduzir corretamente o texto, considerando o exercício concluído;

b) Compreendeu, mas cometeu pequenos erros de grafia na escrita do texto. Nesse caso, a grafia correta é apresentada para que o aluno tenha conhecimento dela, considerando o exercício concluído;

c) Não compreendeu. Nessas circunstâncias, o sistema fornece ao aluno duas opções: (i) sugere que ele acesse "pistas" no sistema; (ii) acompanhe um vídeo mostrando as frases sendo pronunciadas pausadamente para facilitar a compreensão. Em seguida, o exercício é repetido para que o aluno consolide a compreensão, após o que é considerado concluído.

Além disso, a ferramenta permitirá a criação de material didático complementar às aulas, de modo que o aluno exercite e desenvolva, no seu próprio ritmo, as habilidades de pronúncia, percepção auditiva e ortográfica. Os exercícios relativos a essas aulas serão criados também a partir da associação de imagens, diálogos gravados e o texto correspondente aos diálogos. Será ainda associado, a cada exercício, um conjunto de "pistas" que podem ser escolhidas entre novos textos, sons, imagens ou vídeos. Pretende-se que as pistas possam ser associadas à lição como um todo e/ou a palavras específicas dentro de cada diálogo, de forma que, se o aluno não souber como escrever uma das palavras por não ter compreendido sua pronúncia, receberá uma pista relativa a essa palavra. Por exemplo, se no módulo básico de um curso de inglês o texto ouvido foi "this is a pencil" e o aluno não conseguiu identificar a última palavra, escrevendo "this is a pen”, então o sistema lhe apresentará a imagem de um lápis, ao mesmo tempo em que pronunciará o som "pencil".

0 agente autor é o responsável pela criação das situações envolvendo histórias com imagens e diálogos gravados, que o aluno usará no curso. Utilizando os recursos multimídia (microfone, câmera de vídeo, videocassete etc.), 
o autor desenvolverá um curso atraente, fazendo com que os aprendizes e consequentemente os alunos sintam-se motivados.

0 representante do aluno no sistema é o agente aprendiz. Assim, cada aluno que utilizar o sistema terá um agente aprendiz a representálo. 0 aprendiz assimila as capacidades de aprendizagem do aluno, construindo o seu perfil. 0 conhecimento das habilidades do aluno servirá para sugerir ao autor formas diferentes de ministrar o conteúdo da matéria na expectativa de aumentar a sua eficiência e eficácia. Por outro lado, poderá servir também ao professor, como uma forma de testar novos métodos ou exercícios. Cada agente aprendiz terá o conhecimento do perfil de aprendizagem do aluno que representa. Por ele, o aluno terá ingresso às aulas que The estarão disponíveis com acesso às imagens e sons, mas não ao texto dos diálogos. Na verdade, a principal atividade do aluno será tentar reproduzir o texto oculto após ouvir uma ou mais vezes o som do diálogo gravado, utilizando ou não as pistas. A ferramenta lhe disponibilizará uma caixa de diálogo com as diversas indicações para responder às situações apresentadas que permitirá plena interação entre o aluno e o sistema. Por meio de uma janela serão transmitidas as informações na sequência do diálogo. Nessa fase, será usado como critério de comparação um algoritmo que conta a quantidade de palavras escritas. Se o número de palavras escritas difere do objetivo, então um erro importante ocorreu. Se, por outro lado, o número de palavras coincidir e os erros de grafia corresponderem a fonemas semelhantes, como ph e f, em inglês, para graphics e grafics, por exemplo, então ocorreu apenas um erro "por pouco”. Caso contrário, serão erros importantes. O sistema não apresentará a resposta correta enquanto o aluno cometer erros importantes. As opções serão a repetição do texto, até que a audição permita a identificação das palavras e das pistas. Essa prática coincide com a que normalmente é feita por um professor humano em sala de aula. Quando o aluno não cometer mais erros ou apenas erros "por pouco", então o sis- tema considerará que o objetivo da lição foi conseguido e apresentará ao aluno a correta grafia das palavras.

0 agente administrador gerencia o sistema e, portanto, deverá interagir com todos os agentes presentes. Como observador externo das atividades do agente autor e da evolução dos agentes aprendizes, o administrador poderá servir como um "crítico" das metodologias didáticas adotadas. Essa informação, aliada ao retorno dado pelos aprendizes ao autor, contribuirá para métodos e técnicas de ensino mais orientadas à finalidade de ensino do idioma pertinente. 0 conhecimento que lhe é associado está relacionado com as tarefas de administração do sistema como configuração e estatísticas de desempenho. É por meio dele e de seu cadastramento que o usuário terá acesso à ferramenta. Nesse momento, além das boas-vindas, o administrador pedirá ao candidato algumas informações básicas como:

a) Qual o curso que deseja fazer? Ou qual a língua que deseja aprender?

b) Qual o seu nível de conhecimento da língua (inicial, médio, avançado, conversação, outro)? Se a resposta do aluno for inicial, ele lhe dá explicações sobre o curso e o funcionamento do sistema; faz com ele um exercício de acesso ao material das aulas do seu nível; e o insere no programa. Se a resposta não for inicial, ele é convidado a fazer um teste a fim de determinar o nível em que deve iniciar o curso pretendido. Ao final do teste, o aluno recebe informações acerca da sua situação e do nível em que ele deve ingressar. Em seguida, ele recebe instruções sobre o curso e o funcionamento do sistema; é convidado a fazer um rápido exercício para acessar o material das aulas, ao final do qual é informado que está apto a usar o sistema e é inserido no programa, no nível recomendado.

Em cada aula (em cada seção), a participação do aluno se dará via agente administrador, que o encaminha ao aprendiz. 
0 agente ajuda estará à disposição do aprendiz para auxiliá-lo na realização das lições. Além disso, identificará quais as principais dificuldades do aluno pela categorização das dúvidas mais frequentes. Essa informação também poderá contribuir para melhoria de apresentação dos recursos a cargo do agente autor. Por outro lado, o próprio agente ajuda poderá adaptar-se, elaborando "dicas" mais orientadas às necessidades do aluno. 0 agente ajuda terá o conhecimento associado às formas mais eficazes de prestar auxílio aos agentes do sistema, em particular aos aprendizes.

0 relacionamento dessas quatro estruturas de agentes que permitirá a troca de conhecimento sempre que um necessitar de informações do outro, e será objeto de definição durante a elaboração do software e da implementação da ferramenta.

Cada curso (idioma) será ministrado em três módulos: básico, intermediário e avançado, que serão detalhados durante a elaboração da ferramenta e sua respectiva implementação.

A ferramenta contemplará um sistema de avaliação periódica de sua eficiência e eficácia, via satisfação do usuário, em função da aprendizagem do aluno. Essa avaliação contemplará os recursos pedagógicos de texto, som, imagem etc. e uso do sistema. Será baseada em indicadores relacionados ao processo de aprendizagem colaborativa, conforme Collazos et al. (2007), devidamente adaptados a essa realidade. Para esse efeito, os alunos responderão a um questionário, cujas respostas e sugestões, depois de compiladas, servirão de apoio para implementar melhorias no sistema. lsso implica na utilização de um protocolo de comunicação bem definido e eficiente, com recursos de explicitação da informação transmitida, na qual as ontologias, cujo papel no processo de Engenharia do Conhecimento é basicamente facilitar a construção de um modelo de domínio, serão utilizadas. Além disso, uma ontologia proverá um vocabulário de termos e relações para os quais um domínio pode ser modelado, portanto, será usada para orientar a extração e a integração de informações relevantes a par- tir de várias fontes estruturadas. Isso servirá para preencher a lacuna entre as conceitualizações de informação, tanto do ponto de vista do usuário, quanto das oferecidas pelas várias fontes de informação. Esse caráter multimídia da representação da informação atende à necessidade de aplicação de diferentes métodos de ensino, que podem variar de acordo com o assunto, com a língua em estudo ou com as habilidades de aprendizagem do aluno.

A ferramenta será implementada por uma equipe constituída por profissionais da área de tecnologia da informação e comunicação, profissionais da área de engenharia e gestão do conhecimento, informática e professores de idiomas, inicialmente inglês e francês, os primeiros a serem implementados.

\section{Considerações finais}

Imediatamente após a disponibilização da ferramenta na Web, haverá um período de "validação" pelo usuário de cerca de seis a doze meses, que será monitorado pela equipe de implementação. Nesse período, no momento da “inscrição", o aluno será informado dessa situação e convidado a colaborar nesse processo. Para isso, na medida em que usar a ferramenta, preencherá um formulário, disponibilizado no sistema, no qual colocará suas críticas, observações e sugestões para melhorá-lo. Esse material será automaticamente enviado à equipe, que o analisará e realizará na ferramenta os ajustes necessários, visando otimizá-la.

A ferramenta oferecerá as vantagens de um sitema de ensino de idiomas estrangeiros, inicialmente, inglês e francês, disponível permanentemente na lnternet. Isso criará oportunidade para que um grande número de pessoas possa estudar um idioma estrangeiro, de acordo com suas conveniências, tempo e horário disponível, em qualquer lugar que disponha de um computador conectado à Internet. Essa facilidade, além de proporcionar oportunidade para que um grande número de pessoas tenha oportunidade de estudar língua estrangeira, favorecerá uma possí- 
vel política social de aquisição de computadores comunitários para uso de pessoas de baixa renda, constituindo um salto qualitativo sociocultural no tocante ao ensino e à aprendizagem de lígua estrangeira, particularmente no Brasil.

\section{Conclusões}

O sistema multiagentes oferece condições consistentes para servirem de base à construção e implementação da ferramenta proposta.

A ferramenta a ser implementada sobre base de sistemas multiagentes se configurará como um grande avanço no binômio ensino e aprendizagem de língua estrangeira, uma vez que a comunicação e cooperação operadas pelos agentes são similares às que ocorrem entre pessoas da sociedade humana para realizar determinadas atividades.

Essa ferramenta de autoria, disponível continuamente na Internet, apresentará a flexibilidade que normalmente não têm os cursos tradicionais de línguas estrangeiras. Além da vantagem de iniciar um curso em qualquer período, local e horário, oferecerá a possibilidade de retomá-lo em qualquer período no caso de ter ocorrido uma paralisação.

A ferramenta possibilitará o acesso a cursos de língua estrangeira a qualquer pessoa, em qualquer horário ou local que disponha de computador conectado à Internet.

Aqueles que têm facilidade e tempo para progredir mais rapidamente no aprendizado de língua estrangeira serão beneficiados, pois aprenderão a língua de seu interesse em períodos mais curtos.

A ferramenta a ser implementada pode ser, futuramente, um produto a ser utilizado e disseminado por escolas públicas, universidades e empresas.

A validação a ser feita pelos usuários do sistema e a avaliação periódica a que será submetida permitirão ajustes que lhe concederá eficácia constante.

\section{Referências bibliográficas}

AINSWORTH, S. Using a single authoring environment across the lifespan of learning. Educational Technology \& Society, Hellas, v. 10, n. 3, p. 22-31. 2007.

ARAÚJJO, M. M. S. de. 0 pensamento complexo: desafios emergentes para a educação on-line. Revista Brasileira de Educação, Rio de Janeiro, v. 12, n. 36, p.515-551, set./dez. 2007.

BAILEY, B. P.; KONSTAN, J. A. Authoring interactive media. In: WEBSTER, J. G. (Ed.). Encyclopedia of electrical and electronics engineering. New York: John Wiley \& Sons, 2000.

BARR, A.; COHEN, P. R.; FEIGENBAUM, E. A. The handbook of artificial intelligence. v. 1. Los Altos, California: Addison-Wesley, 1990.

BECK, J.; STERN, M.; HAUGSJAA, E. P. Applications of Al in education. The ACM Digital Library, Montreal, v. 3, n. 1, p. 11-15, sep. 1996. Disponível em: <http://www.acm.org/crossroads/xrds3-1/aied.html>. Acesso em: 3 set. 2007.

BRASIL. Lei n. 9.394, de 20 de dezembro de 1996. Estabelece as Diretrizes e Bases da educação nacional. Legislação, Brasília, DF, dez. 1996. Disponível em: <http://www.planalto.gov.br/ccivil_03/LEIS/I9394.htm>. Acesso em: 18 nov. 2003.

BULTERMAN, D. C. A.; HARDMAN, L. Structured multimedia authoring. ACM Transactions on Multimedia Computing, Communications and Applications, Broadway/New York, v. 1, n. 1, p. 89-109, feb. 2005. 
CLANCEY, W. J.; SOLOWAY, E. Artificial intelligence and learning environments. Artificial Intelligence. Amsterdam, v.1, n. 42, p. 1-6, feb. 1990.

COLLAZOS, C. A. et al. Evaluating collaborative learning processes using system-based measurement. Educational Technology \& Society, Hellas, v. 10, n. 3, p. 257-274, 2007.

COURTILLON, J.; RAILLARD, S. A. Français langue étrangere: cours credif. Paris: Didier, 1983.

COUTAZ, J. Interfaces homme-ordinateur: conception et réalisation. Paris: Bordas, 1990.

CRISPIM, H. A. F.; ABDALLA JR, H.; MOLINARO, L. F. R. Proposta para um ambiente inteligente de ensino a distância. In: CONGRESSO INTERNACIONAL DE EDUCAÇÃO A DISTÂNCIA, 9., 2002. Vila Mariana-SP. Anais... São Paulo: Associação Brasileira de Educação a Distância, set. 2002. p. 36-53. Disponível em: <http://www.abed.org.br/congresso2002/trabalhos/ texto48.htm>. Acesso em 24 out. 2007.

FIALHO, F. A. P.; ALVES A. G. Agentes cognitivos na educação. In: CONGRESSO BRASILEIRO DE COMPUTAÇÃO, 1, 2001. Itajaí. Anais... Itajá: Sociedade Brasileira de Computação, 2001. v. 1, p. 173-183.

GEYMER, C. F. R. et al. SistEma Multiagente de Ensino e Aprendizagem na Internet (SEMEAl). 2003. Disponível em: <http:/ /www.inf.ufes.br/ sbie2001/figuras/artigos/a068/a068.htm>. Acesso em: 2 set. 2007.

GILBERT, D. A.; MANNY, A. Intelligent Agent Strategic, 1996. Disponivel em: <http://activist.gpl.ibm.com:81/WhitePaper/ ptc2.html>. Acesso em: 4 set. 2007.

HEILMANN, K. et al. Intelligent agents: a technology and business application analysis, 1995. Disponível em: <http:// haas.berkeley.edu/ heilmann/agents/index.tml>. Acesso em: 13 set. 2007.

KASKALIS, T. H.; TZIDAMIS, T. D.; MARGARITIS, K. Multimedia authoring tools: the quest for an educational package. Educational Technology \& Society, Hellas, v. 10, n. 3, p. 135-162, 2007.

LÉVY, P. Cibercultura. Tradução de Carlos Irineu da Costa. São Paulo: Editora 34, 2000.

MCARTHUR, D. J.; LEWIS, M.; BISHAY, M. The roles of artificial intelligence in education: current progress and future prospects. Santa Monica: Rand Corporation, 2002.

MORAN, J. M. Contribuições para uma pedagogia da educação on-line. In: SILVA, M. (Org.). Educação on-line. São Paulo: Loyola, 2003.

MORIN, E. Os sete saberes necessários à educação do futuro. Tradução de Catarina Eleonora F. da Silva e Jeanne Sawaya. 9. ed. São Paulo: Cortez; Brasília: UNESCO, 2004.

O'CONNOR, D. O. et al. Intelligent agents strategy: white paper, IBM Corporation, Research Triangle Park, North Caroline, 1996. Disponível em: <http://activist.gpl.ibm.com/WhitePaper/ptc2.html>. Acesso em: 6 set. 2007.

OLIVEIRA, F. M. de. Advances in artificial intelligence. In: BRAZILIAN SYMPOSIUM ON ARTIFICIAL INTELLIGENCE, 14, 1998. Porto Alegre. Proceedings... Porto Alegre: Sociedade Brasileira de Inteligência Artificial, Springer, 1998. p. 54-73.

OLIVER, M. An introduction to the evaluation of learning technology. Educational Technology \& Society, Hellas, v. 4, n. 3, p. $20-$ 30, oct. 2000.

PETTENATI, M. C. et al. The learning tutor: a web based authoring system to support distance tutoring. Educational Technology \& Society, Hellas, v. 3, n. 4, p. 151-164, oct. 2000.

PIAGET, J. Psicologia da inteligência. 2. ed. Rio de Janeiro: Zahar, 1983.

RAMOS, E. M. F. Educação e informática: reflexões básicas. Florianópolis, 1996. Disponível em: <http://www.edit.inf.ufsc.br:1998/ album99/referencias/Q1.htm>. Acesso em: 9 set. 2007. 
ROSSETTI, A. G. et al. Proposta de um ambiente multiagente para ensino de língua estrangeira multimídia. In: CONFERÊNCIA SULAMERICANA EM CIÊNCIA E TECNOLOGIA APLICADA AO GOVERNO ELETRÔNICO, 3, 2006, Curitiba. Anais..., III CONeGOV. Florianópolis: Digital ljuris, 2006. v. DVD, p. 47-54.

SANTOS, C. T. doS; OSÓRIO, F. S. Um ambiente virtual inteligente e adaptativo para a educação a distância. In: SIMPÓSIO BRASILEIRO DE INFORMÁTICA NA EDUCAÇÃO, 14, 2003. Rio de Janeiro. Anais... Rio de Janeiro: NCE - IM/UFRJ, 2003.

URBAN-LURAIN, M. Intelligent tutoring systems: an historic review in the context of the development of artificial intelligence and educational psychology, 1998. Disponível em: <http://www.cse.msu.edu/ urban/TS.htm>. Acesso em: 13 set. 2007.

VIRVOU, M.; MOUNDRIDOU, M. A Web-based authoring too for algebra-related intelligent tutoring systems. Educational Technology \& Society, Hellas, v. 3, n. 2, p. 61-70, apr. 2000.

WIDDOWSON, H. G. 0 ensino de línguas para comunicação. Tradução de José Carlos P. de Almeida Filho. Campinas: Pontes, 1991.

Recebido em 17.04.08

Aprovado em 01.12.08

Adroaldo Guimarães Rossetti é pesquisador da Embrapa Agroindústria Tropical e doutorando em Engenharia e Gestão do Conhecimento-EGC da Universidade Federal de Santa Catarina-UFSC.

Almir dos Santos Albuquerque é analista de Sistemas do Tribunal de Justiça de Rondônia e doutorando em Engenharia e Gestão do Conhecimento-EGC da Universidade Federal de Santa Catarina-UFFSC. E-mail: almir@egc.ufsc.br

Vasco Pinto da Silva Filho é professor da Universidade Federal de Rondônia-UNIR e doutorando em Engenharia e Gestão do Conhecimento-EGC da Universidade Federal de Santa Catarina-UFSC. E-mail: vasco@egc.ufsc.br

José Leomar Todesco é doutor em Engenharia de Produção e professor da Pós-graduação em Engenharia e Gestão do Conhecimento-EGC da Universidade Federal de Santa Catarina-UFSC. E-mail: tite@stela.ufsc.br

Fernando Álvaro Ostuni Gauthier é doutor em Engenharia de Produção e professor da Pós-graduação em Engenharia e Gestão do Conhecimento-EGC da Universidade Federal de Santa Catarina-UFSC. E-mail: gauthier@inf.ufsc.br 